CUPAUAM 25.2, 1999, pp. 251-265

\title{
REFLEXIONES SOBRE UNA PRODUCCIÓN PECULIAR DE CERÁMICA COMÚN ROMANA LOCALIZADA EN EL TERCIO NORTE DE LA PENÍNSULA IBÉRICA Y EL SUR DE AQUITANIA. LOS MATERIALES DE LA CIUDAD DE GIJÓN (ESPAÑA) ${ }^{[1]}$
}

\author{
CARMEN FERnÁNDEZ OCHOA \\ Departamento de Prehistoria y Arqueología. Universidad Autónoma de Madrid \\ MAR Zarzalejos PRIETO \\ Sección de Patrimonio Histórico \\ Delegación Provincial de Educación y Cultura de Albacete (JCCM)
}

\section{Resumen}

En este trabajo se realiza una revisión sobre un lote homogéneo de cerámicas comunes procedentes de diversas excavaciones realizadas en la ciudad de Gijón. Su presencia en la región norteña peninsular y la Aquitania francesa y su amplitud cronológica -siglos I-V d.C.- permiten adelantar hipótesis de trabajo acerca del posible significado de estas producciones.

Palabras clave: Cerámica romana/Arqueometría/Comercio

\begin{abstract}
At this article we present a preliminary study about some potteries found on sites at Gijon city (Asturias, Spain) during 4th century A.D. These materials are present too on north of Spain and the west of France during 1 st- 5 th century A.D. This information permits to show some work lines about its meaning.
\end{abstract}

Key words: Roman pottery/ Archaeometry/Ancient trade

[1] Este artículo fue elaborado en 1999, a raíz de la presentación previa, en sendas monografias, de los materiales hallados en las intervenciones que, bajo la dirección de $\mathrm{C}$. Fernández Ochoa, se han venido realizando durante la pasada década en diversos solares de la ciudad de Gijón. Con este trabajo pretendemos dar mayor difusión al registro de estos materiales en este núcleo cantábrico, al tiempo que abundar algo más en algunas de las propuestas de interpretación que se hicieron en su dia (Fernández Ochoa, 1994; Fernández Ochoa y Zarzalejos, 1997). Cuando el trabajo se encontraba cerrado y entregado para su edición, hemos tenido acceso a una nueva aportación de A. Martínez Salcedo, centrada monográficamente sobre este particular ("Apunte para el estudio de las cerámicas comunes no torneadas de época romana en el País Vasco Peninsular: el caso de las ollas peinadas de borde vuelto plano", Kabie, XXV, 1998/99, Bilbao, 161-182), en la que se hace referencia a nuestras publicaciones previas. Dada la imposibilidad de introducir cambios de mayor alcance en la estructura del texto que esta nota, se realizarán las oportunas referencias bibliográficas en otros trabajos futuros que se encuentran en preparación sobre los materiales hallados en las Termas de Campo Valdés. 


\section{INTRODUCCIÓN}

En los últimos tiempos han asomado repetidamente al panorama bibliográfico unas producciones de cerámica común romana cuyo análisis comienza a plantear interrogantes del mayor interés. Se trata de un conjunto bien perfilado en cuanto a formas, tecnología y decoración, que registra una dispersión geográfica que afecta, según los datos conocidos, a una amplia zona comprendida entre la región galaica nororiental, el alto Valle del Ebro, la cornisa cantábrica y el S de Aquitania. Los materiales exhumados en las excavaciones arqueológicas practicadas en diferentes puntos del casco urbano gijonés se suman a la larga nómina de yacimientos que testimonian su presencia (Fernández Ochoa, 1994; Fernández Ochoa, 1995; Fernández Ochoa y Zarzalejos, 1997).

El análisis completo de estas producciones se encuentra aún en sus inicios. De hecho, hasta hace poco tiempo los investigadores que habían de afrontar su estudio y catalogación partían del supuesto de que se trataba de cerámicas de difusión local o regional, según parecía desprenderse del aspecto descuidado de sus superficies y de sus formas esencialmente relacionadas con el repertorio de cocina. Sin embargo, la publicación de conjuntos que amplían substancialmente su área de dispersión geográfica y, sobre todo, la difusión de los primeros análisis arqueométricos, hacen pensar que nos hallamos ante una realidad diferente, tanto desde el punto de vista ceramológico, como funcional y económico.

$\mathrm{El}$ presente estudio pretende efectuar un acercamiento a estas producciones aportando nuevos datos cronológicos -derivados de las excavaciones urbanas de Gijón- y unas hipótesis preliminares que permitan avanzar en el conocimiento de una especie cerámica muy común en las regiones cantábricas de Hispania y Aquitania.

\section{CARACTERIZACIÓN TECNOLÓGICA Y ARQUEOMÉTRICA}

Los materiales de Gijón han permitido identificar la presencia de dos grupos bien caracterizados desde el punto de vista analítico. Establecemos su distinción a partir de las diferencias tecnológicas observables a simple vista y acreditadas a través de análisis arqueométricos. Se trata fundamentalmente de ollas, platos y cuencos, cuyos rasgos morfológicos específicos serán comentados con mayor detenimiento más adelante. En el marco de nuestros estudios sobre la cerámica común de Gijón, estos materiales aparecen siempre citados como grupos 2 y 3 . La ordenación de los datos conocidos sobre ambos grupos seguirá la propuesta realizada recientemente por Pérez Arantegui et alii (1996, 74 ss.).

\section{Grupo 2}

\section{- Rasgos de identificación visual}

El grupo 2 se define por el empleo de barros compactos, con desgrasantes finos y fractura irregular. Resultan bastante características las superficies homogéneamente areno- 


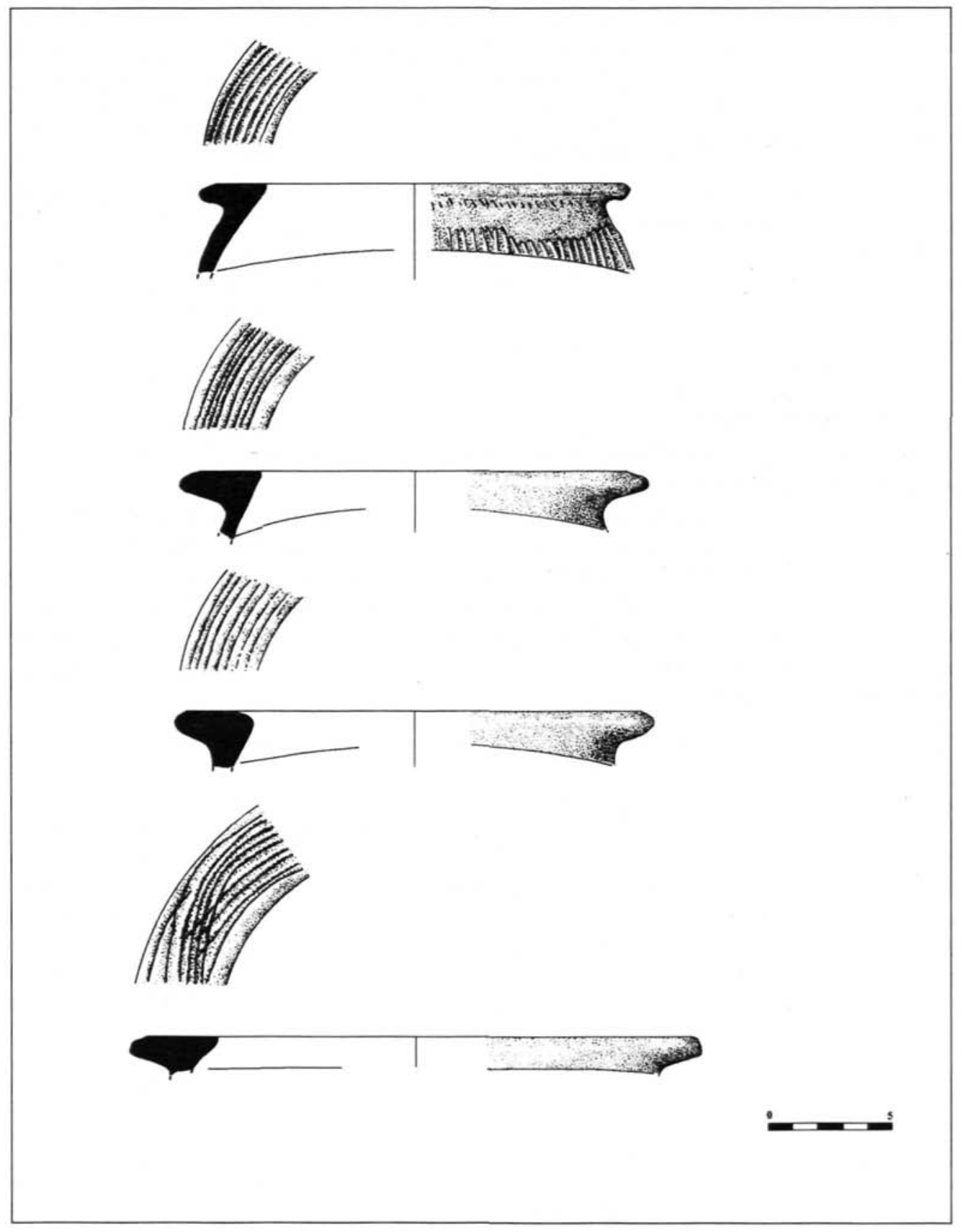

Figura 1: Ollas de borde plano horizontal halladas en los estratos tardorromanos de la muralla de Gijón 
sas, con una distribución muy uniforme de las partículas. Es posible que se empleara para su modelado un torno lento o torneta. Las piezas presentan cocciones mixtas, con nervio grisáceo y son frecuentes los acabados alisados. Las ollas pueden mostrar decoración incisa en el borde y la pared.

\section{- Caracterización petrográfica}

Los análisis petrográficos aplicados a muestras de este grupo identifican una pasta arcillosa con abundantes inclusiones de litología variada y tamaño fino $(0,5-1 \mathrm{~mm})$. En opinión de P. Lapuente ${ }^{[2]}$, la homogeneidad en tamaño de estos clastos podría ser indicativa de una adición intencionada para modificar la plasticidad de la arcilla. Entre los componentes identificados en los distintos análisis figuran fragmentos de rocas metamórficas (cuarcitas, esquistos, pizarras, filitas, micacitas, mármoles, anfibolitas), micas (biotita, moscovitas) y calcita.

\section{- Zona de origen}

Las muestras de estas características pertenecientes a yacimientos del valle del Ebro, presentan, con carácter accesorio, fragmentos de rocas volcánicas, tipo traquita con epidotas. La localización de esos elementos permite a la autora antes citada, situar el origen de estas arcillas a lo largo del valle medio-bajo del río Aragón Subordán, en su confluencia con el Aragón, y posiblemente a lo largo de la Canal de la Berdún, ya sea en la provincia de Zaragoza o en la de Navarra. Las muestras de Gijón no han presentado restos de estas rocas volcánicas, aunque su composición es prácticamente idéntica. Conviene anotar que el número de inclusiones de este tipo en cada muestra es muy limitado, por lo que su ausencia podría ser accidental ${ }^{131}$.

Por otra parte, un estudio reciente presentado en el Congreso de Dijon en 1996 aborda un ensayo de sistematización acerca del origen y difusión de estos tipos cerámicos (Rechin e Izquierdo et alii, 1996). La analítica aplicada sobre muestras procedentes del S de Aquitania, el País Vasco y Navarra permite diferenciar al menos tres grupos de pasta, uno de los cuales -grupo II b- podría mostrar equivalencias con el que estamos identificando en Gijón, en virtud de la presencia de materiales sedimentarios asociados a rocas metamórficas y plutónicas (Rechin e Izquierdo et alii, 1996, 415). Este grupo se localiza mayoritariamente en yacimientos emplazados al S de los Pirineos y, a modo de hipótesis, se propone su procedencia de los entorno de Peñas de Aya (Ibidem, 416).

\footnotetext{
[2] Pilar Lapuente Mercadal, profesora del Dpto. De Cristalografia y Mineralogía de la Universidad de Zaragoza, ha realizado gentilmente análisis de muestras gijonesas y establecido las pertinente comparaciones con materiales aparecidos en yacimientos del valle del Ebro. Sus conclusiones provisionales han sido corroboradas por el análisis realizado por Rosario García Giménez, profesora del Dpto. de Química Agrícola de la U.A.M.

[3] Ante los interesantes problemas planteados por esta cuestión estamos realizando más análisis sobre muestras seleccionadas de este grupo, a fin de concretar la completas identidad de estas piezas gijonesas.
} 


\section{Grupo 3}

\section{- Rasgos de identificación visual}

El grupo 3 está tipificado por pastas muy porosas y poco decantadas, con desgrasantes gruesos/muy gruesos aflorando en superficie y fractura muy irregular. Como sucede en el grupo anterior, quizá se empleara el torno lento para la elaboración de los recipientes. Las superficies, a lo sumo, han sido objeto de un alisado, aunque son frecuentes las piezas de acabado grosero. Suelen presentar coloración grisácea en ambas superficies, y algunos fragmentos muestran nervio de cocción. También en este caso, las ollas pueden presentar decoración incisa en el borde y la pared.

\section{- Caracterización petrográfica}

Este grupo presenta una definición petrográfica caracterizada por una pasta arcillosa de grano muy fino con micas, con una gran cantidad de inclusiones de litología menos variada que el grupo anterior. El tamaño de estos clastos es bastante diverso -desde limo a arena gruesa-, hecho que en opinión de P. Lapuente, podría ser indicativo de una falta de selección de las arenas, o bien de una adición intencionada realizada con un tamizado de $2 \mathrm{~mm}$ de malla.

Las inclusiones más características son los fragmentos de rocas graníticas y sus componente minerales (cuarzos, feldespatos y micas); además contienen rocas metamórficas (esquistos). No presenta fragmentos de rocas sedimentarias.

\section{- Zona de origen}

Esta caracterización se corresponde con el segundo de los grupos identificados en el conjunto de materiales procedentes de yacimientos del valle del Ebro y parece afín al grupo de pastas ya determinado en la analítica practicada sobre materiales aquitanos, vascos y navarros (Rechin e Izquierdo et alii, 1996, 415). Según P. Lapuente, el área de producción habría de situarse en un entorno próximo a un macizo hercínico con ambos tipos de rocas (graníticas y metamórficas). En el momento actual de la investigación, la autora citada opina que resulta arriesgado concretar más en la localización del taller, si bien descarta que el centro estuviera ubicado en la comarca de La Cinco Villas, ya que está alejada de cualquier núcleo paleozoico hercínico y los ríos que la surcan no proceden de un Paleozoico con la litología citada. Esta conclusión no coincide con las hipótesis barajadas por Rechin e Izquierdo, quienes entre sus propuestas defienden como posible la procedencia de este grupo en el ámbito geográfico antes mencionado (Ibidem, 416).

\section{LAS FORMAS}

Desde el punto de vista formal, pese a no haber llegado a nosotros ningún ejemplar íntegro, el grupo de ollas representado en los conjuntos gijoneses muestra cuerpo de tendencia ovoide, borde plano horizontal, o triangular, según prefiere denominarlas C. Aguarod (1994) y base plana. A menudo reciben decoración incisa a peine sobre el borde y la pared. Esta modalidad de recipiente se mantiene dentro de pautas prácticamente inva- 


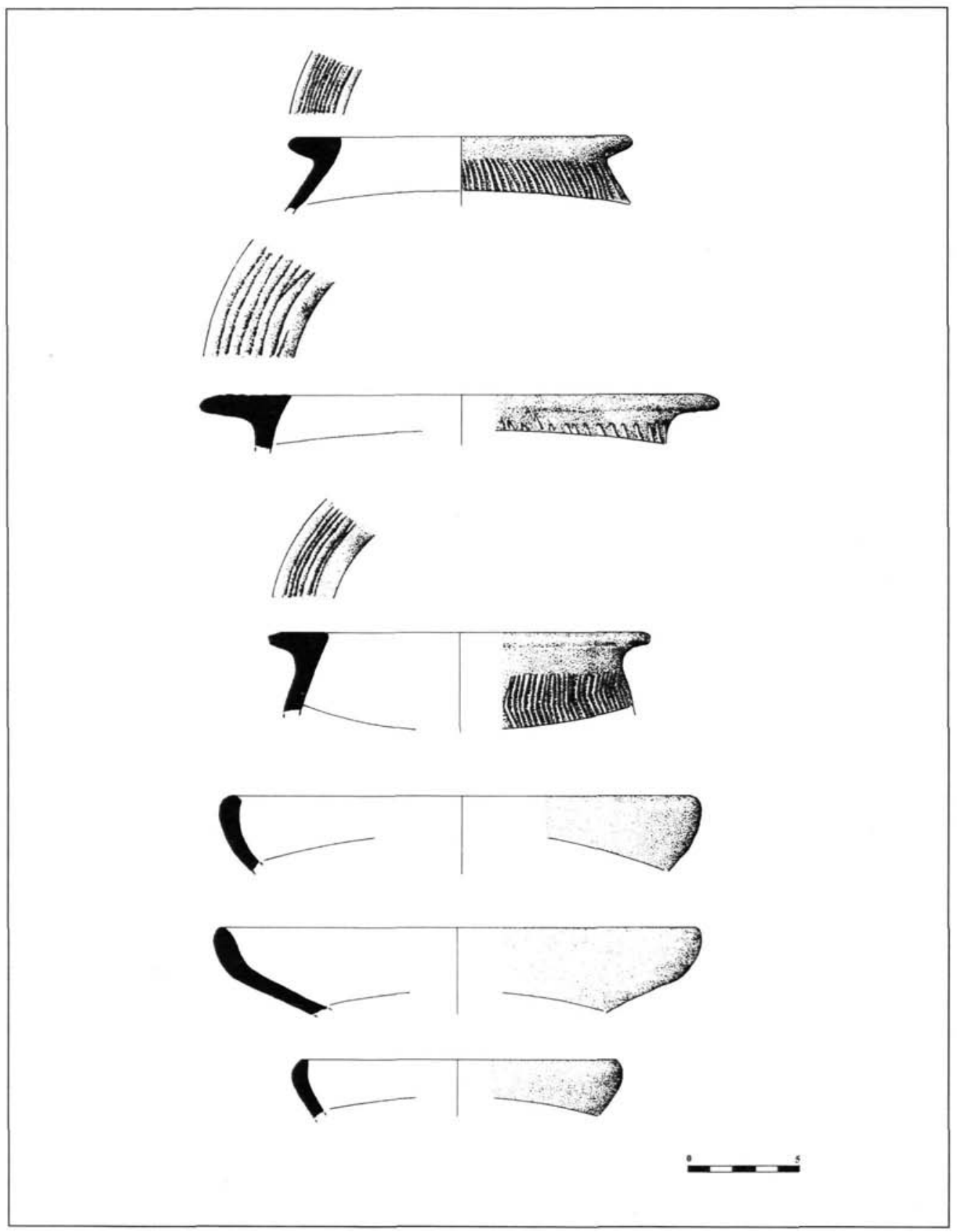

Figura 2: Ollas de borde plano horizontal y platos-tapadera hallados en los estratos tardorromanos de la muralla de Gijón 
riables a lo largo de la fase tardorromana de las estratigrafías de la muralla (Fernández Ochoa y Zarzalejos, 1997, fig.6,76, fig.7, 77; fig. 50, 36; fig.54,29; fig, 55, 30). Algunos ejemplares del sondeo D-7 han sido dados a conocer muy recientemente (Fernández Ochoa, 1995, fig.3, $\mathrm{n}^{\circ} 4$; fig.5, $\mathrm{n}^{\circ} 3-4$; fig.6, $\mathrm{n}^{\circ} 1-3$; fig.7, $\mathrm{n}^{\circ} 6$ ). Asociados a esta modalidad de ollas y con atributos técnicos insertables en los grupos técnicos que estamos tratando, se encuentran platos y cuencos. El material con que contamos está bastante fragmentado, circunstancia que no siempre posibilita la asignación de las piezas a una u otra categoría. No obstante, aquellos ejemplares que conservan mayores proporciones de perfil permiten ilustrar la existencia de grandes platos de pared oblicua con borde engrosado hacia el interior (Fernández Ochoa y Zarzalejos, 1997, fig.30, 96, 97; fig.42, 206; fig.43, 210) o de borde afilado (Ibidem, fig.42, 207), platos con fuerte inflexión entre el borde y el fondo (Ibidem, fig. $30,99,100$; fig. 43,211$)$ y platos de pared oblicua, borde almendrado bien individualizado y fondo plano (Ibidem, fig.42, 208-1; fig.43, 209). Entre los cuencos se identifican perfiles de pared oblicua con borde engrosado al exterior (Ibidem, fig.22, 22-1; fig.43, 212), de pared ligeramente exvasada y borde sencillo de sección redondeada (Ibidem, fig.22-21).

Restaría, por último, comentar la presencia de bordes de jarras asimilados a los grupos que estamos comentando. No corresponden a variantes formales unitarias. Entre ellas se identifican ejemplares de borde en forma de "L" (Fernández Ochoa y Zarzalejos, 1997, fig.44, 221), borde vertical con labio engrosado al exterior (Ibidem, fig.36, 141) o pequeños fragmentos que conservan el pico vertedero del recipiente (Ibidem, fig.44, 222).

\section{LA CRONOLOGÍA}

El conjunto de materiales perteneciente a los grupos tecnológicos 2 y 3 se encuentra asociado a estratos datables a partir de fines del siglo III d.C., siendo especialmente frecuente en contextos del siglo IV d.C. Esta evolución de signo ascendente se percibe con nitidez en las deposiciones del sondeo D-7 de la muralla de Gijón. En los estratos VIII y VII se documenta su aparición en los contextos gijoneses con una presencia relativa que supone para el grupo 3, el $57 \%$ y para el grupo 2 el $13,3 \%$ de los totales de cerámica común. En el estrato VI la superioridad la ostenta el grupo 2 con un $45,9 \%$ mientras que el grupo 3 disminuye a un $13,5 \%$. El descenso del registro material asociado a los estratos IV y V impide una valoración ponderada de su comportamiento, pero lo que sí se advierte es su mantenimiento en los estratos tardoantiguos, donde aparecen aún fragmentos de olla sin modificaciones formales apreciables.

Hemos reseñado la presencia de estos productos en Gijón en el estudio de las salazones de la Plaza del Marqués (Fernández Ochoa, 1994, 56-7) y en un reciente trabajo sobre la fase tardorromana de esta ciudad (Fernández Ochoa, 1995). La abundancia de estas piezas se corrobora, una vez más, al recoger la totalidad del material de los sondeos de la muralla y al realizar la clasificación preliminar de los conjuntos cerámicos exhumados en las termas de Campo Valdés.

El marco cronológico que la circulación de estas piezas acredita en Gijón coincide substancialmente con la evidencia recogida en el inventario realizado por Rechin e Izquierdo et alii (1996, 410-412). Salvo algunos hallazgos de atribución temporal dudosa, 
sólo una corta lista de lugares presentan estos materiales en contextos altoimperiales: Calle Belén (Cantabria), Cascante y Santacara (Navarra), Varea (La Rioja), Santa Elena de Irún (Guipúzcoa), Bayonne, Dax, Tilh y Moliets (Landes). Este registro en cronologías tempranas parece apuntar, como ya indicó en su día C. Aguarod (1994, 141), que nos hallamos ante una producción cuyo arranque puede situarse en el siglo I d.C. No obstante, la abrumadora presencia de esta cerámica en niveles del siglo IV e inicios del V d.C., hace de ella una especie de intenso desarrollo en época tardía. En este sentido, creemos que una de las vías de análisis que deberá sondearse en el futuro es la búsqueda de patrones de definición formal de las producciones altoimperiales y tardías. En efecto, hasta el presente, la atribución de fechas que se ha venido aplicando a estos materiales es la derivada de su pertenencia a contextos con fósiles directores que hacen posible el enmarque cronológico de los mismos. Sin embargo, es necesario emprender un estudio que integre todo el material conocido intentando comprobar si se introducen modificaciones al normotipo original generado en el siglo I d.C. sobre patrones de arraigada tradición en el utillaje cerámico prerromano. En otras palabras, es preciso indagar en las relaciones existentes entre rasgos morfológicos y cronología, con el fin de delinear el perfil de la posible evolución que experimenta esta especie, sólo aparentemente, inmovilista en el curso de varios cientos de años. A este respecto podría apuntarse como dato a tener en cuenta la observación realizada por Barandiarán, Martín Bueno y Rodríguez $(1999,95)$ sobre la tendencia evolutiva de los perfiles desde las formas ovoides a las más globulares, en tanto que los bordes se muestran algo más inclinados. En cualquier caso, éstas son cuestiones merecedoras de un tratamiento pormenorizado y mucho más completo que el que pretendemos plantear en este trabajo preliminar.

\section{ALGUNAS PROPUESTAS SOBRE LA FUNCIÓN Y EL SIGNIFICADO DE ESTAS PRODUC- CIONES CERÁMICAS}

Tradicionalmente se ha considerado que las ollas y platos/cuencos de estas producciones eran de fabricación local dada su tosquedad y falta de valor intrínseco. Los recientes trabajos de C. Aguarod (1991 y 1994) han arrojado nueva luz sobre estas cerámicas cuya presencia es constante en Asturias y en amplias zonas del Alto Ebro, País Vasco, Cantabria y León, llegando hasta la región galaica nororiental ${ }^{[4]}$. Tras la publicación de C. Aguarod la nómina de piezas se ha ampliado considerablemente, pues a los hallazgos gijoneses cabe sumar, en la cornisa cantábrica, los del Bajo Bidasoa (Benito et alii, 1995, 48-51), los de Irún (Barandiarán et alii, 1999, 87 ss.), los de la Ensenada de Portuondo (Martínez y Unzueta, 1995, 111-116, fig.5-13) y los de Flaviobriga (Iglesias y Ruiz, 1995, 47, fig.13) y en el interior, los de León (Liz y Amaré, 1993, 100, fig. 20), Astorga ${ }^{[5]}$ y Lugo (Alcorta, 1994,

\footnotetext{
[4] A través de la nómina de hallazgos publicados es evidente que esta distribución geográfica no se restringe al ámbito vascón con una dispersión por las cuencas alta y media del Ebro, tal y como afirman Barandiarán et alii (1999, 95).

[5] Conocemos la presencia de estos materiales en la capital asturicense por comunicación oral de V. García Marcos a quien agradecemos, una vez más, su desinteresada información.
} 

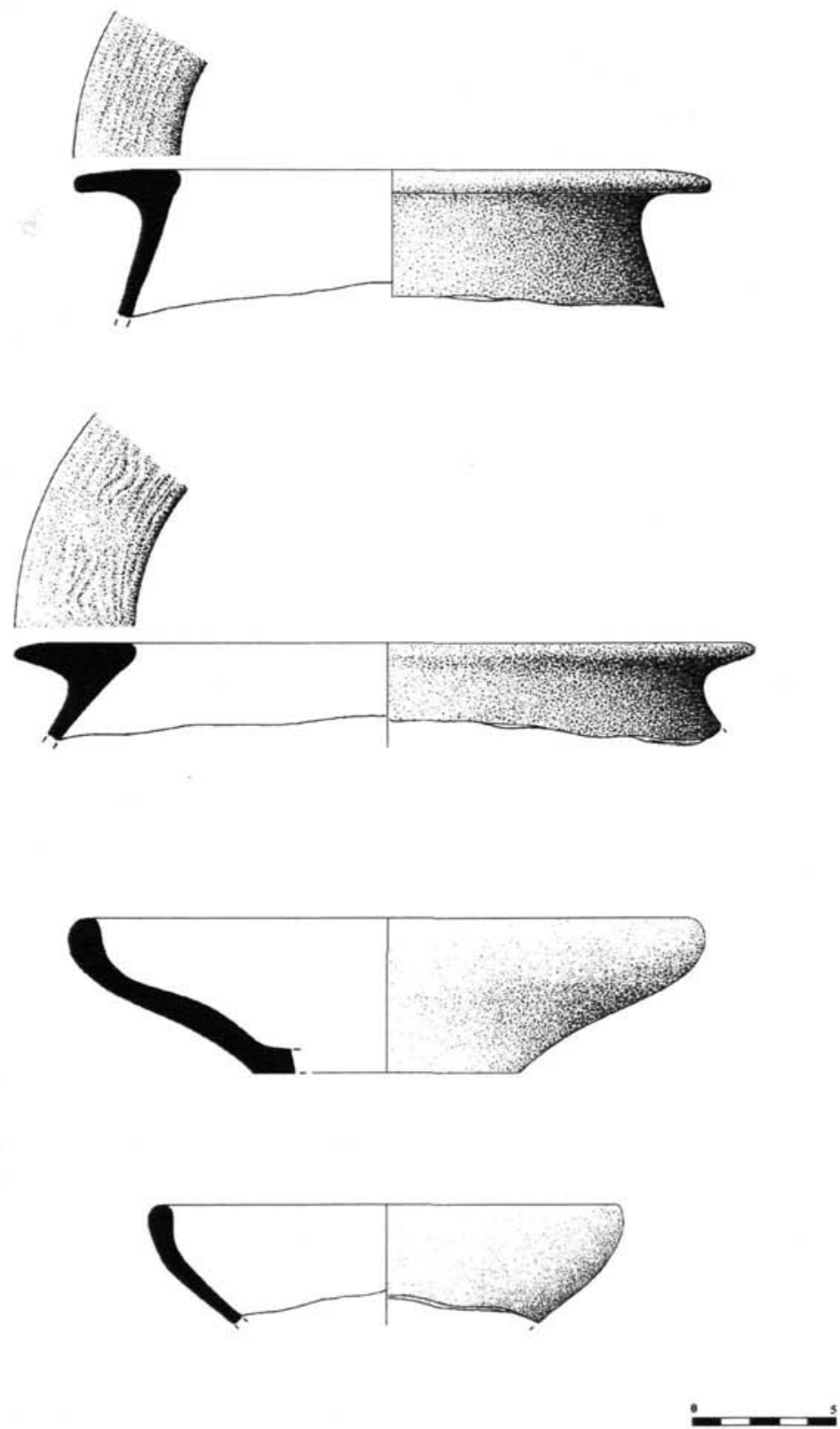

Figura 3: Ollas de borde plano horizontal y platos-tapadera hallados en la factoría de salazones de la Plaza del Marqués de Gijón 
211, fig. 7, 4). La importante dispersión de estos productos en las zonas indicadas no admite lugar a dudas acerca de su carácter norteño dentro de la geografía peninsular, sin que descartemos su posible localización en la Meseta Norte una vez que se ha procedido a su caracterización, como razonamiento lógico si se considera la interconexión de este ámbito con las comarcas costeras. Además, la presencia de estos productos significativamente se constata también en el S de Aquitania (Rechin, 1997, 604-606; Rechin e Izquierdo et alii, 1997), introduciendo interesantes posibilidades para su valoración económica, según comentaremos después (Fig.4).

Más problemático es establecer si su fabricación se realizó a escala local o regional, dado que no han sido identificadas hasta el presente en ningún centro productor. El cruce de análisis practicados sobre materiales galos e hispanos resulta, a nuestro juicio, bastante revelador. Según los datos obtenidos se pueden identificar al menos tres grupos petrográficamente diferenciados, dos de los cuales tienen representación prioritaria al sur de los Pirineos. En efecto, los grupos $2 \mathrm{a}$ y $2 \mathrm{~b}$ ) de Rechin e Izquierdo podrían ser afines a los grupos 1 y 2 de Aguarod y Lapuente, equivalentes a los grupos 2 y 3 de Gijón. Según hemos apuntado más arriba, no es fácil concretar la zona exacta de origen de los barros. Para Lapuente, el grupo 1 podría localizarse en el valle medio-bajo del Aragón-Subordán y posiblemente en la Canal de Berdún, mientras que el grupo 2 presenta más problemas de identificación aunque esta autora descarta su origen en la comarca de las Cinco Villas. En todo caso, existen datos suficientes para argumentar que, al menos una parte de esta producción radicaría en el valle del Ebro. Dado que los materiales de Gijón se ajustan a la composición de los grupos identificados en este espacio geográfico, nos hallaríamos ante una fabricación cerámica con capacidad para difundir sus productos en ámbitos supra comarcales. La confirmación de estas redes comerciales que incorporan en sus circuitos bienes aparentemente vulgares, se sumaría a la certeza que ya tenemos sobre la difusión de las vajillas de mesa. Esto obliga a incidir nuevamente en lo superado de los planteamientos que defendieron a ultranza la autarquía y el carácter estrictamente local de los usos cerámicos en el mundo tardorromano.

Otro asunto que conviene comentar es el de la funcionalidad de estas cerámicas. Tradicionalmente estos recipientes se han incorporado entre las series de la cerámica de cocina aplicadas a procesos culinarios en caliente ${ }^{[6]}$. Su aspecto tosco, el predominio formal de ollas y platos, así como los restos negruzcos presentes en ellos han resultado definitorios para mantener esta atribución, incluso en trabajos monográficos de aparición muy reciente (Rechin e Izquierdo et alii,1997, 409).

Últimamente se ha insinuado la posibilidad de que se tratara de una producción relacionable con el transporte de salazones (Martínez y Unzueta, 1995, 112). El indicio que manejan estos autores es la identificación de posibles marcas incisas antes de la cocción situadas sobre el borde. En los casos identificados en Portuondo (Vizcaya) y Gijón, se trata de una " $\mathrm{V}$ " o una "A" sin travesaño. A la nómina de lugares que presentan estos autores, podríamos agregar el ejemplar de Los Bañales, también con el signo indicado, y uno de

[6] Esta interpretación se sigue sustentando en estudios recientes (Barandiarán et alii, 1999, 95). 


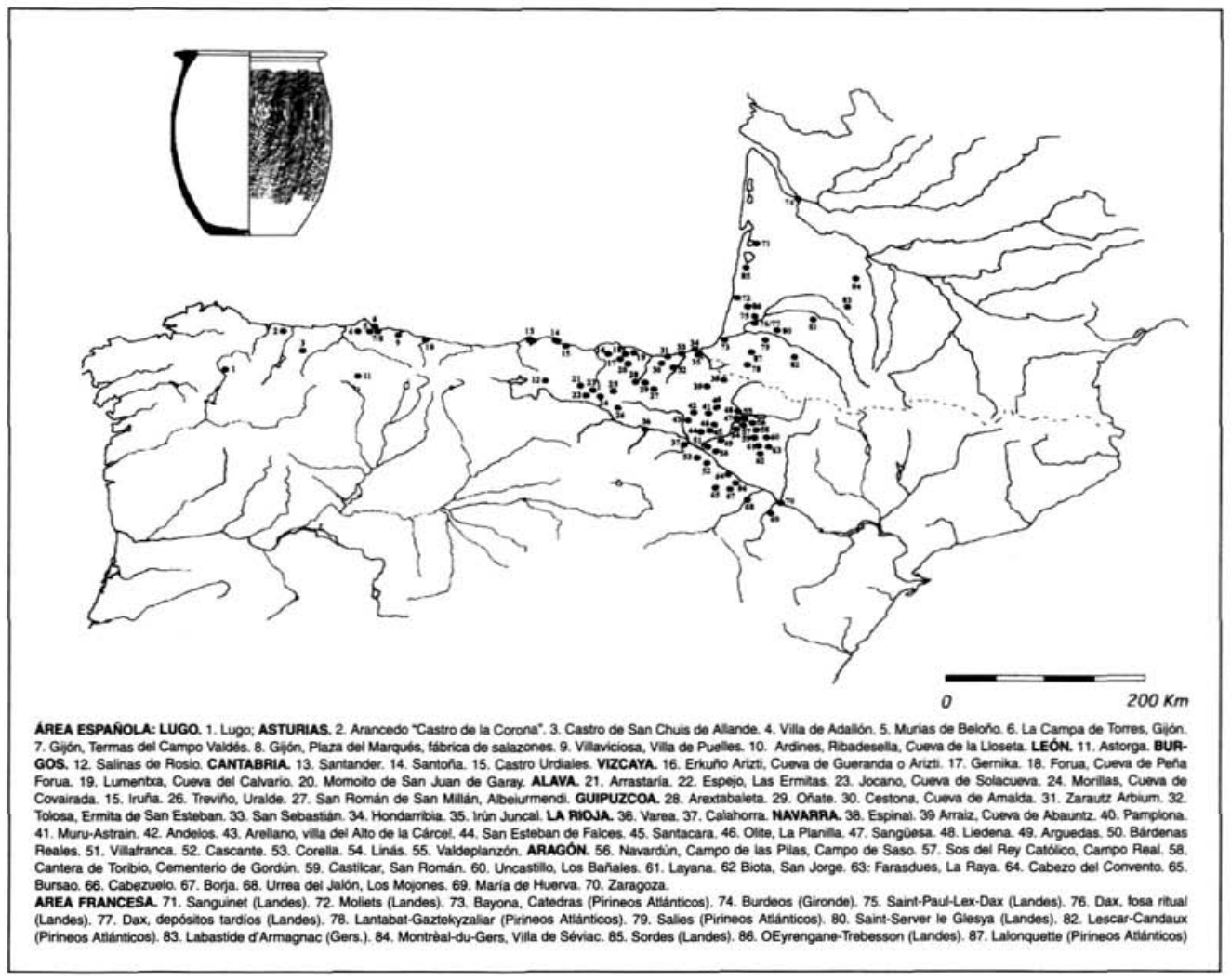

Figura 4: Dispersión de las ollas de borde plano horizontal (Adaptación de C. Fernández Ochoa y M. Zarzalejos Prieto)

Pompaelo, donde aparece una cruz, o mejor, una "X" (Aguarod, 1994, 142, fig. 17,2 y 4). Trabajando con la parca, y desde luego parcial, información que proporcionan estos dos últimos ejemplos, hemos constatado que la posible marca "V" o "A" se encuentra sobre una olla de $18 \mathrm{~cm}$. de diámetro, dimensiones que curiosamente coinciden con las del ejemplar gijonés de la Plaza del Marqués $(18 \mathrm{~cm}$.). Por su parte, la pieza de Pompaelo que presenta una " $\mathrm{X}$ " mide unos $28 \mathrm{~cm}$. Alertadas por estas observaciones hemos procedido a comprobar las dimensiones de los ejemplares de Gijón y a compararlos con los de otros yacimientos publicados, por si pudiera derivarse alguna conclusión, teniendo en cuenta que los diámetros calculados a partir de fragmentos normalmente arrojan cierto margen de error. Aún considerando esta limitación, hemos comprobado que existen, al menos, tres categorías de los diámetros del borde. La primera ilustra ejemplares que pudiéramos considerar de tamaño pequeño, con diámetros comprendidos entre los 11,4 y $15 \mathrm{~cm}$. Un segundo grupo estaría formado por las ollas de proporción media, entre 16 y $20 \mathrm{~cm}$. Por último, contamos con un tercer grupo de piezas de dimensiones mayores, entre 20 y $28 \mathrm{~cm}$., aunque 
en Gijón no se han encontrado, por ahora, ollas de tamaño extremo como el que presenta la marca " $\mathrm{X}$ " en Pompaelo. Este resultado parece sugerente de cara a proponer la posibilidad de que las marcas actúen como indicadores de capacidad o de peso del contenido, pero debemos advertir la limitación que supone la ausencia de piezas completas que permitan asegurar el volumen de los recipientes. Como propuesta inicial sugerimos que el posible numeral "V" pudiera aludir a un contenido con peso de cinco libras (1635 gr.) y, por ende, la marca " $X$ " se correspondiera con diez libras (3270 gr.). Esta hipótesis se asienta en el supuesto de que la materia transportada fuese de naturaleza sólida o semilíquida (vid infra).

Otro asunto que inmediatamente se plantearía es el de la cubrición de los envases, a fin de permitir la estanqueidad para su transporte por vía terrestre. A modo de ensayo, hemos constatado que el importante conjunto de platos/cuencos que acompaña estratigráficamente a las ollas de Gijón y en todos los yacimientos donde éstas se documentan, presenta grupos de diámetros asociables a las dimensiones de las bocas de las ollas. A esta constatación se suma otra aún más interesante, cual es la presencia de restos negruzcos sobre algunos bordes de olla y en el interior de los llamados platos/cuencos. Este indicio podría encontrar corroboración en otros yacimientos, según puede leerse entre líneas a través de alguna descripción ${ }^{[7]}$. Nos planteamos, en consecuencia, que tal vez los platos/cuencos fueran en realidad las tapaderas de las ollas y que se empleara pez para realizar el sellado. El borde plano horizontal de las ollas obligaría a superponer la tapadera a modo de casquete, sin encajar en ranura alguna, rellenando el espacio entre el borde del contenedor y el operculum con pez. Esta particular manera de cubrición, lógicamente induce a pensar que el diámetro de la cubierta supere al de la olla. Muy recientemente, C. Aguarod ha estudiado un conjunto de ollas para conservas procedentes de Celsa. Esta autora realiza una propuesta a partir de los análisis de Rottlánder sobre la utilidad de las vasijas que presentan impregnación negra en el borde (Beltrán Lloris et alii, 1997). La pez sería utilizada bien para impermeabilizar los recipientes, bien para proceder a su sellado. Esta última función es la que conviene, a nuestro juicio, a los materiales que ahora nos ocupan.

De la esencia de nuestra propuesta restaría un punto importante por resolver, cual es el hecho de que las presuntas marcas de capacidad se sitúan siempre sobre el labio de las ollas, de tal manera que, de cubrirse con los "platos-tapadera", esta información quedaría oculta para los compradores del producto. Nos planteamos, ante esta evidencia, que la marca sería significativa sólo para el proceso de envasado, si bien al hilo de nuestra argumentación, la diferenciación de tamaños que hemos observado haría innecesaria la marca de capacidad. A pesar de todo, no encontramos otra explicación plausible para la ejecución de los signos que aparecen sobre estas vasijas, puesto que la expresión de las marcas de officina sobre producciones cerámicas tradicionalmente se suelen ajustar a otras modalidades y fórmulas epigráficas, aunque podría tratarse de algún tipo de control interno del

[7] A título de ejemplo, M. Esteban se refiere en estos términos a un ejemplar de olla de "Cerámica común local" procedente de la cueva Antón Koba (Onate): "Un fragmento de borde, cuello e indicio de cuerpo que se ajusta tipológicamente a las "ollae" de cuerpo globular y borde vuelto plano, conserva restos de una impregnación de color negro intenso sobre el borde y bajo él, extendiéndose hacia el inicio del cuerpo." (Esteban, 1990, 335). 
alfar. En el marco de estas disgresiones, que no son más que hipótesis de trabajo, también podríamos barajar otra posibilidad de cubrición ajena a los platos/tapadera, que ocluyera únicamente el orificio de cierre salvando el borde. Este opérculo podría estar realizado en material perecedero o en cerámica, como sucede con los envases anfóricos. En este último caso, hemos de indicar que, al menos en Gijón, no hemos identificado aún elementos que pudieran servirnos de apoyo en este sentido.

Otro problema a considerar en relación con las cuestiones que ahora tratamos es el del origen de los envases como tales y sus contenidos. Entre las hipótesis de trabajo que podrían manejarse se contarían las siguientes:

1. Que las ollas fueran en realidad envases de salsamenta u otros productos concentrados derivados de la transformación de pescado, según proponen algunos autores (Martínez y Unzueta, 1995, 112). Obviamente, las áreas que estarían facultadas para ello serían las riberas del Cantábrico, donde, por otro lado, se vienen detectando instalaciones relacionadas con estas actividades (Fernández Ochoa y Martínez Maganto, 1994, 169-170). Ahora bien, si se confirmara que los focos de producción de las ollas radicaron en el valle del Ebro, no parece muy lógico desvincular la fabricación de continente y contenido. Este hecho encarecería notablemente el producto.

2. Que las ollas funcionaran como envases de otro producto, cuya naturaleza no es fácil de calibrar en el actual estado de la cuestión, pero que formara parte de la riqueza natural de la zona en la que se fabrican los envases. El acabado de estas cerámicas -superficies groseras, simples alisados y carencia de engobes- las hace más adaptables a productos sólidos o semilíquidos. La consideración apriorística de que se trataba de recipientes de uso culinario motiva que estos materiales sean lavados sin realizar análisis previos de posibles adherencias relacionadas con su contenido. En nuestra opinión, la configuración de estas vasijas y sus tamaños las harían aptas para el transporte de productos cuyo interés radica no tanto en la cantidad cuanto en su eficiencia en pequeñas dosis para determinados usos alimenticios. A tal efectos, nos preguntamos si este objeto de comercio pudo ser la miel, edulcorante natural de uso imprescindible en el mundo antiguo y cuyas producciones peninsulares obtuvieron fama desde tiempos remotos.

Otro asunto de gran interés reside en la distribución geográfica de estos materiales y en su presencia predominante en contextos de época tardorromana. Si bien los yacimientos donde se documentan son de tipología variada (ciudades, necrópolis, villae, etc.), no es menos cierta su presencia reiterada en centros urbanos de interés estratégico en la trama administrativa y económica del Bajo Imperio, localizados en el arco atlántico hispano-galo. Ello nos induce a proponer, a modo de hipótesis, la inserción de este producto en las redes de distribución que canalizan la recaudación de impuestos hacia el limes. En efecto, la difusión geográfica de estos materiales se ajusta a la vertebración de la red de comunicaciones vigente en el Bajo Imperio y de manera especial observamos su estrecha relación con la llamada Via Annonaria, tanto en su tramo terrestre (Fuentes, 1996) como en su réplica marítima (Fernández Ochoa, 1997, 252-9). 

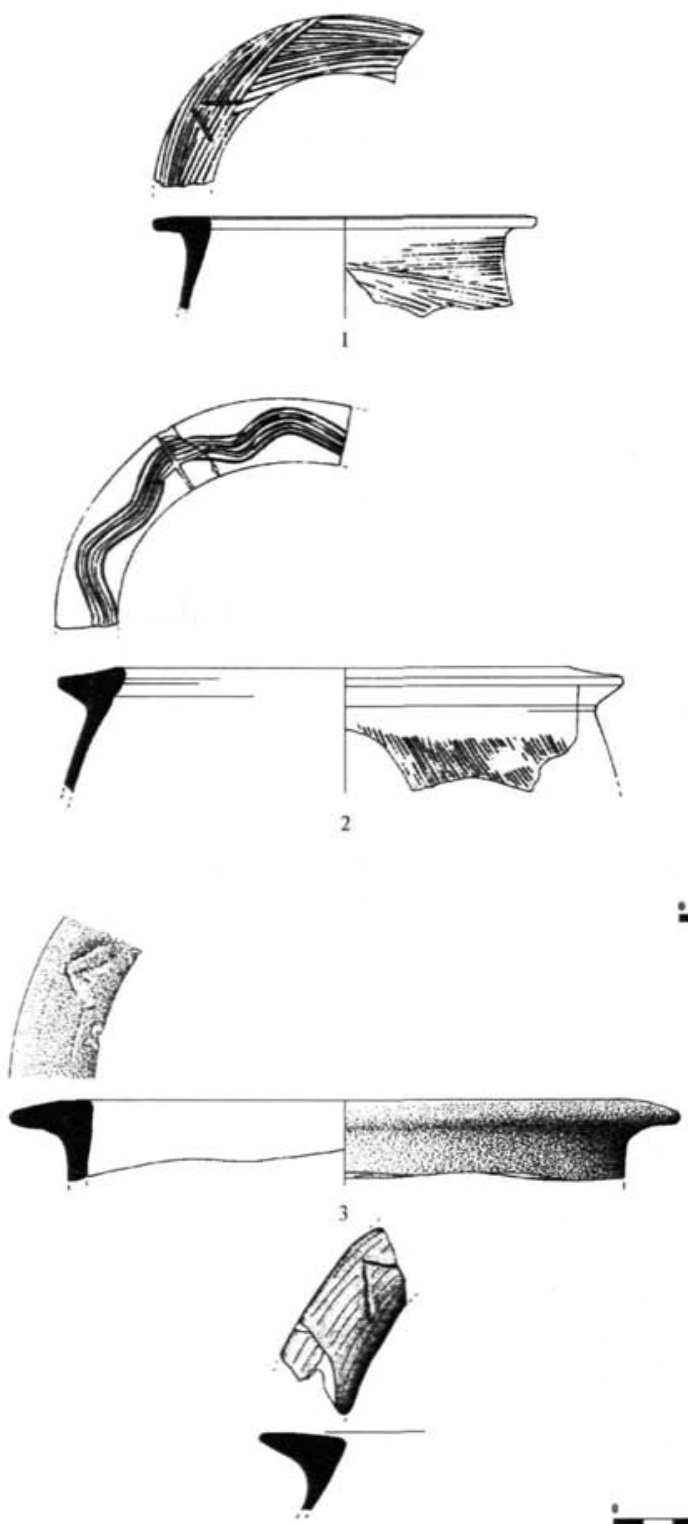

4

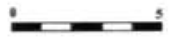

Figura 5: Bordes de ollas con marcas incisas: 1. Factoría de salazones de la Plaza del Marqués (Gijón). 2. Los Banales (Zaragoza) (Según C.Aguarod). 3. Pompaelo (Pamplona) (Según C. Aguarod).

4. Portuondo (Vizcaya) (Según Martínez y Unzueta). 


\section{BIBLIOGRAFÍA CITADA EN EL TEXTO}

AGUAROD, C. (1991): Cerámica romana importada de cocina en la Tarraconense, Zaragoza.

AGUAROD, C. (1994): "La cerámica común de producción local-regional e importada. Estado de la cuestión en el Valle del Ebro", Ceràmica comuna romana dépoca altoimperial a la Península Ibérica. Estat de la cuestió, Monografías Emporitanas, VIII, Empúries.

ALCORTA, E.J. (1994): "Avance al estudio de la cerámica común romana de cocina y mesa de Lucus Augusti", Ceràmica comuna romana d'época altoimperial a la Península Ibérica. Estat de la cuestió, Monografías Emporitanas, VIII, Empúries.

BARANDIARÁN, I., MARTÍN-BUENO, M. y RODRÍGUEZ SALIS, J. (1999): Santa Elena de Irún. Excavación arqueológica de 1971 y 1972, Colección Oiasso, 1, Irún.

BELTRÁN LLORIS, M. et alii, 1997: Colonia Victrix Iulia Lepida-Celsa (Velilla de Ebro, Zaragoza. Celsa II. Los Materiales de la Casa de los Delfines, Zaragoza.

BENITO, A.M., ESTEBAN, M. e IZQUIERDO, M. (1995): El Bajo Bidasoa en época romana, Irún.

ESTEBAN, M. (1990): El País Vasco Atlántico en época romana, San Sebastián.

FERNÁNDEZ OCHOA, C. (1994): Una industria de salazones de época romana en la Plaza del Marqués (Gijón), Gijón.

FERNÁNDEZ OCHOA, C. (1995): "Gijón en el Bajo Imperio: La evidencia arqueológica", Congreso Internacional La Hispania de Teodosio, vol.2, Segovia 1997.

FERNÁNDEZ OCHOA, C. y MARTÍNEZ MAGANTO, J. (1994): "Las industrias de salazón en el Norte y Noroeste de la Península Ibérica. Nuevas aportaciones", Archivo Español de Arqueología, 67, Madrid.

FERNÁNDEZ OCHOA, C. y ZARZALEJOS, M. (1997): "El registro arqueológico II. Estudio de materiales", en Fernández Ochoa, C.: La muralla romana de Gijón (Asturias), Madrid.

FUENTES, DOMÍNGUEZ, A. (1996): "La romanidad tardía en los territorios septentrionales de la Península Ibérica", Coloquio Internacional Los Finisterres Atlánticos en la Antigüedad. Época prerromana y romana, Gijón.

IGLESIAS GIL, J.M. y RUIZ, A. (1995): Flaviobriga. Castro Urdiales romano, Castro Urdiales.

LIZ GUIRAL, J. y AMARÉ, M.T. (1993): Necrópolis tardorromana del Capus de Vegazana y las producciones latericias de la Legio VII Gémina, León.

MARTÍNEZ SALCEDO, A. y UNZUETA, M. (1995): "El asentamiento de la ensenada de Portuondo (Pedernales-Mundaka, Bizkaia)", Kobie, XXII.

PÉREZ ARANTEGUI, J. et alii (1996): Arqueometría y caracterización de materiales arqueológicos, Cuadernos del Instituto Aragonés de Arqueología, IV, Teruel.

RECHIN, F. (1997): "Le faciès céramique aquitain, exemples et réflexions méthodologiques", Isturitz, 9, (I Coloquio Internacional sobre la Romanización en Euskal Herria, vol.2), Donostia.

RECHIN, F, IZQUIERDO, M. T. et alii, (1997): "Céramiques communes non tournées du Nord de la Péninsule Ibérique et d'Aquitaine Meridionale. Origine et difussion d'un type particulier de pot culinaire", S.F.E.C.A.G., Actes du Congrès de Dijon (1996), Marseille. 